\title{
COMA WITH GLYGOSURIA NOT DUE TO DIABETES MELLITUS
}

BY

\author{
G. B. FLEming, B.A., M.D., AGNES HERRING, M.B., Ch.B., and \\ NOAH MORRIS, M.D., D.Sc.
}

(From the Department of Paediatrics, Glasgow University, and the Biochemical Laboratory, Royal Hospital for Sick Children, Glasgow.)

It is well known that glycosuria with hyperglycaemia does not necessarily indicate true diabetes mellitus. The association, however, of coma with glycosuria, even though acetonuria is only slight, almost inevitably leads to the diagnosis of diabetic coma.

The first two cases described in this paper were admitted in profound coma and had abundant sugar in the urine. They were at first looked on as examples of diabetic coma but subsequently it became evident in both that the symptoms were due to another cause.

Case 1. J. McG., a boy of eleven years was admitted to hospital on January 29, 1929. At the age of two weeks he was treated surgically for a depressed fracture of the left frontal region. Apart from measles in early childhood he had been healthy till six months before admission. At that time he began to have attacks of headache and giddiness followed by vomiting which occurred about once a week and lasted for a day. Two weeks before admission vomiting occurred every second morning and a week later the boy was noticed to be very drowsy. Vomiting ceased for two days and then recurred in association with constipation and severe headache. On the day before admission the headache became more severe and on the same evening the boy became comatose and was sent to hospital early next morning (1 a.m.) as a case of meningitis.

On admission the patient was found to be a well-nourished boy in a semi-comatose condition. Physical examination revealed no abnormality in the heart, lungs and abdomen. Kernig's sign was present but nuchal rigidity was only slight. Lumbar puncture was performed and 40 c.c. of clear cerebrospinal fluid was withdrawn under greatly increased pressure: the cell count was 13 per c.mm. and the Pandy test negative. The urine was found to contain abundant sugar and a moderate amount of acetone and diacetic acid.

Treatment was carried out immediately on the assumption that the condition was one of diabetic coma. Twenty units of insulin and $20 \mathrm{gm}$. of glucose were given: the boy soon regained consciousness. Six hours later $(9$ a.m.) the blood-sugar was $75 \mathrm{mgm}$. per 100 c.c. and the urine contained but a trace of sugar. The child now was bright and intelligent. His weight was $27.68 \mathrm{kgm}$. Physical examination revealed no abnormality 
except that the right pupil was larger than the left and ophthalmoscopic examination showed optic neuritis in both eyes with numerous haemorrhages. Vision appeared to be normal and no restriction in the field of vision of either eye could be detected. On closer inquiry into the history it was found that the attacks of headache had been accompanied by vertigo, diplopia and dimness of vision but that there was no apparent defect between the attacks. A skiagram of the skull showed slight separation of the sutures, a large pituitary fossa with erosion of the posterior clinoid process and areas of calcification above the sella.

Four days after admission (30.1.29) a blood-sugar curve after $29 \mathrm{gm}$. glucose (1 gm. per $\mathrm{kgm}$. body weight) gave the following result :-

$\begin{array}{ccccccc}\text { FASTING } & \frac{1}{2} \text { HOUR } & 1 \text { HOUR } & 1 \frac{1}{2} \text { HOURS } & 2 \text { HOURS } & & \\ 106 & 211 & 209 & 191 & 122 & \text { MGM. PER } 100 \text { C.C. }\end{array}$

Sugar was present in the urine obtained one hour after ingestion of glucose.

Three weeks later (23.2.29) the blood-sugar curve after $29 \mathrm{gm}$. glucose gave the following result:-

$\begin{array}{ccccccc}\text { FASTING } & \frac{1}{2} \text { HOUR } & 1 \text { HOUR } & 1 \frac{1}{2} \text { HOURS } & 2 \text { HOURS } & & \\ 109 & 204 & 216 & 106 & 67 & \text { MGM. PER } 100 \text { C.C. }\end{array}$

There was no glycosuria.

On 4.3.29 the blood-sugar curve after $29 \mathrm{gm}$. glucose was

$\begin{array}{ccccccc}\text { FAsting } & \frac{1}{2} \text { HOUR } & 1 \text { HOUR } & 1 \frac{1}{2} \text { HOURS } & 2 \text { HOURS } \\ 136 & 313 & 331 & 211 & 109 & \text { MGM. PER } 100 \text { c.C. }\end{array}$

Sugar was present in the half-hour, hour and two hour specimens of urine.

Throughout the boy's stay in hospital (26.1.29 to 7.3.29) specimens of his urine occasionally contained a trace of glucose and glucosazone crystals were recovered.

Four months later (July, 1929) the boy was seen again as an out-patient, when he was found to have put on $9 \mathrm{kgm}$. in weight and showed the Fröhlich type of obesity. On ophthalmoscopic examination the fundi appeared normal. The bloodsugar after $25 \mathrm{gm}$. glucose was as follows :-

$\begin{array}{ccccccc}\text { FASTING } & \frac{1}{2} \text { HOUR } & 1 \text { HOUR } & 1 \frac{1}{2} \text { HOURS } & 2 \text { HOURS } & & \\ 135 & 227 & 241 & 152 & 136 & \text { MGM. PER } 100 \text { c.c. }\end{array}$

There was no glycosuria.

Two years later (October, 1931) his weight was $43.2 \mathrm{kgm}$. , height $147.5 \mathrm{~cm}$. The blood-sugar curve after $43 \mathrm{gm}$. glucose was

$\begin{array}{cccccc}\text { FASTING } & \frac{1}{2} \text { HOUR } & 1 \text { HOUR } & 1 \frac{1}{2} \text { HOURS } & 2 \text { HOURS } & \\ 87 \cdot 7 & 182 & 256 & 204 \cdot 3 & 156 \cdot 2 & \text { MGM. PER } 100 \text { c.C. }\end{array}$

There was sugar and acetone in the specimen of urine obtained one hour after glucose was given.

It is clear that this case is one of supra-pituitary tumour, probably an adamantinoma giving rise to the typical Fröhlich syndrome with a disturbance in carbohydrate metabolism. The symptoms at first pointed 
to a diagnosis of diabetic coma and it was only after further examination and observation that this diagnosis was proved to be unjustified. There can be no doubt, however, that the coma was due to increase in intracranial pressure with stimulation of the centre in the medulla controlling the bloodsugar level or more probably of the anterior pituitary lobe, the hormones of which have contra-insular and ketogenic properties. The association of coma with glycosuria almost automatically led to the diagnosis of diabetic coma. The one feature which was absent from the picture was typical acidotic breathing; this would almost certainly have been present in true diabetic coma.

Case 2. J. W., a boy aged two years, was admitted to hospital on the night of October 13, 1934. The birth and development of the child had been normal. The first tooth was cut at seven months, walking began at nine months, and talking at eighteen months. Except for measles at one year, followed by more or less persistent blepharitis, there had been no other illnesses. There was no history of thirst, polyuria or diarrhoea. On the day before admission the child was well. On the morning of the day of admission he was listless and tired and off his food. In the afternoon he seemed better, but in the evening he was febrile and he vomited. He was put to bed but did not sleep. On being lifted for a moment he suddenly became drowsy and did not recognize his parents. This condition persisted and he was brought to hospital two hours after the onset.

On admission the patient was found to be a pale, punylooking child; he was unconscious but could be roused with difficulty. He lay motionless with closed eyes, breathing regularly but not deeply and showing no sign of air-hunger. The rectal temperature was $101^{\circ} \mathrm{F}$. The pupils were equal and reacted to light, and the eyeballs were of normal tension. Neither nuchal rigidity nor Kernig's sign was present and the plantar reflexes were flexor. There was no oedema. The circulatory and respiratory systems appeared to be normal. The urine was found to contain abundant sugar, a faint trace of acetone, but no albumin or other abnormal constituent. At this time the patient was thought to be in diabetic coma, and was treated accordingly. Unfortunately a blood-sugar estimation was not made that evening. Treatment was carried out immediately; he was given 10 per cent. glucose in normal saline by stomach tube and by rectum (120 c.c. in all) and 10 units of insulin hypodermically. The child came out of coma rapidly. He was given sips of water containing sugar throughout the remainder of the night.

Next morning the child was awake, pale and cross but not thirsty. The urine was sugar-free and contained no ketone bodies. The blood taken at 9 a.m. had the low sugar content of $39 \mathrm{mgm}$. per 100 c.c. As the boy had been given sugar throughout the night this could not be considered a fasting value. The child was put on ordinary diet without insulin. By the afternoon abundant ketone bodies had appeared in the urine. Ketonuria persisted for the next seven days and then ceased. Apart from the specimen of urine obtained on the evening of admission, there was no glycosuria at any time during the child's stay in hospital.

On the morning of the second day in hospital following a twelve-hours' fast a blood-sugar curve was carried out after the 
administration of $9 \mathrm{gm}$. of glucose by the mouth. The results showed a remarkably low fasting blood-sugar and a curve which did not reach the $100 \mathrm{mgm}$. level.

$\begin{array}{cccccc}\text { FAsting } & \frac{1}{2} \text { HOUR } & 1 \text { HOUR } & 1 \frac{1}{2} \text { HOURS } & 2 \text { HOURS } & \\ 28.5 & 66.6 & 96 \cdot 1 & 69 \cdot 2 & 66 \cdot 6 & \text { MGM. PER } 100 \text { C.C. }\end{array}$

A lumbar puncture was carried out. The cerebro-spinal fluid came out under normal pressure, was clear and contained 3 cells per c.mm. Pandy's test was negative. Ophthalmoscopic examination did not reveal any abnormality.

The child continued well on ordinary diet, but always seemed to be hungry and was cross. Three weeks later (November 2) another blood-sugar curve was carried out, this time after the administration of four minims of adrenaline hypodermically. The response was abnormally high.

$\begin{array}{ccccccc}\text { FASTING } & \frac{1}{4} \text { HOUR } & \frac{1}{2} \text { HOUR } & 1 \text { HOUR } & 2 \text { HOURS } & & \\ 125 & 172 \cdot 4 & 215 \cdot 1 & 263 \cdot 1 & 148 \cdot 1 & \text { MGM. PER } 100 \text { c.C. }\end{array}$

On November 6 the fasting blood-sugar was $81.5 \mathrm{mgm}$. per 100 c.c. and on November 30, $81.9 \mathrm{mgm}$. per 100 c.c.

The Wassermann reaction was negative. A skiagram of the skull taken during his stay in hospital showed no abnormality but one taken six months later showed separation of the sutures and ' splaying' of the sella indicating increased pressure. At this time the urine was found to be free from sugar and acetone and the fasting blood-sugar was $76 \cdot 2 \mathrm{mgm}$. per 100 c.c.

There can be little doubt that this is not a case of true diabetes mellitus. The course of the illness is comparable to the metabolic disturbance produced by diabetic puncture, where all available carbohydrate is mobilized and excreted, leaving the tissues in a state of carbohydrate starvation with consequent hypoglycaemia. Presumably in the present case some sudden intracranial disturbance occurred leading to coma and mobilization and excretion of carbohydrate with consequent hypoglycaemia. The appearance of ketonuria twenty-four hours after the onset of the illness can be accounted for by the lack of carbohydrate in the tissues. The later skiagrams yield confirmatory evidence that the metabolic disturbance is related to some intracranial lesion possibly situated in the pituitary region. Whether the pituitary gland itself is involved it is impossible to say. If, however, this is the case it is possible that the glycosuria was due to sudden excitation of the anterior lobe with consequent suprarenal stimulation and inhibition of the action of insulin.

Another child recently observed by us shows clearly the influence of grave cerebral disturbances on the carbohydrate metabolism although in this case glycosuria was absent.

Case 3. E. G., a girl aged one year and eleven months was admitted to hospital on July 10, 1935. The birth was normal and the child remained healthy till three days before admission when she was noticed to be constipated and irritable. At $3 \mathrm{p} . \mathrm{m}$. on the day of admission she suddenly became unconscious with rigid limbs, staring eyes and frothing at the mouth. She is also reported to have vomited. 
On admission to hospital two hours after the onset of the illness she was found to be a moderately well-nourished child, deeply cyanosed and unconscious. The right arm and leg were held rigid and showed occasional twitching. The pupils were dilated and fixed. The knee jerks were active but the abdominal and plantar reflexes could not be elicited. Chvostek's sign was absent. The heart, lungs and abdomen appeared to be healthy. The urine contained neither albumin nor sugar. Lumbar puncture was done shortly after admission. The fluid was under increased pressure; it was clear and contained 3 cells per c.mm. Pandy's test was negative. Temperature $103^{\circ} \mathrm{F}$.

The next morning the child appeared quite well though rather irritable.

The blood-sugar content was estimated at hourly intervals from the time of admission ( 5 p.m.) till midnight and again at $9 \mathrm{a} . \mathrm{m}$. on the following day. The first sample showed $250 \mathrm{mgm}$. sugar per 100 c.c. and there was a gradual fall till the sample obtained twenty-four hours later only contained $36.7 \mathrm{mgm}$. per 100 c.c. (see table).

TABLE.

Case 3. Showing the changes in bloOd-SUgar content.

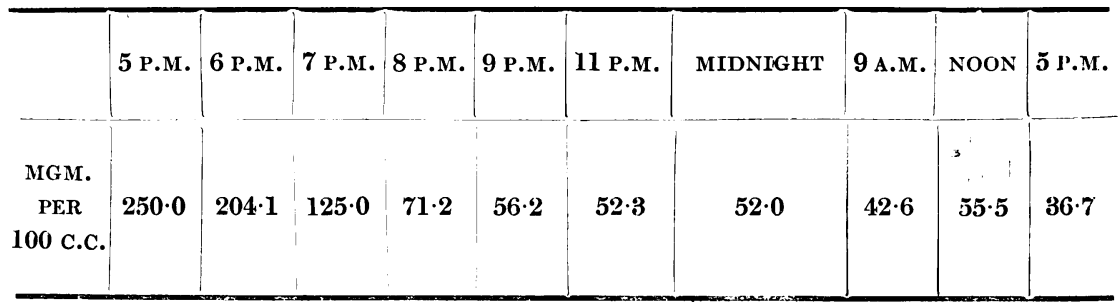

The fasting blood-sugar forty hours after admission was normal ( $82.6 \mathrm{mgm}$. per 100 c.c.) but the blood-sugar curve after $9 \mathrm{gm}$. glucose showed rather a high rise and a delayed fall.

$\begin{array}{cccccccc}\text { Fasting } & \frac{1}{2} \text { HOUR } & 1 \text { hOUR } & 1 \frac{1}{2} \text { HOURS } & 2 \text { HOURS } & & \\ 82.6 & 188.6 & 153.8 & 126.5 & 101 \cdot 0 & \text { MGM. PER } & 100 \text { c.c. }\end{array}$

Eight hours after admission acetone was detected in the urine. A skiagram of the skull showed a suggestion of 'paw-marking ' in the parietal and occipital regions. The sutures did not appear to be separated.

Whatever the cause of the coma, there is clearly present in this case a disturbance of carbohydrate metabolism as indicated by the initial hyperglycaemia followed by hypoglycaemia and acetonuria, though the level of the blood-sugar apparently did not attain a height sufficient to cause glycosuria.

\section{Discussion}

A case in many ways similar to the three we have reported is described by Eckstein ${ }^{1}$.

In this case, a girl of twelve years, who had not previously been known to have diabetes, was admitted to hospital in profound coma, with $9 \cdot 2$ per cent. of sugar in the urine and ketonuria. The blood sugar was $576 \mathrm{mgm}$. 
per cent. She was treated with insulin and injections of glucose. The next day the patient regained consciousness, the excretion of ketones and sugar ceased and although the blood-sugar became normal, convulsions with an extensor plantar reflex occurred after a few hours. During the next few days severe nervous symptoms developed and persisted till she died ten weeks later. At autopsy marked atrophy of the cerebral cortex was found and on histological examination necrosis of the cerebral cortex and hippocampus.

This case was looked on as primarily one of diabetes with secondary involvement of the central nervous system but the fact that sugar disappeared from the urine and that the blood-sugar content returned to normal a considerable time before the girl died suggests that the glycosuria and coma were secondary to disease of the central nervous system. Though the blood-sugar was not estimated at the time, the convulsions and extensor plantar reflex which occurred the day after admission to hospital, suggest a swing over to a condition of hypoglycaemia as occurred in two of the cases here reported. In short it seems probable that the coma and glycosuria were not due to true diabetes mellitus.

The sequence of events in these cases in many ways resembles that reported by Greenwald and Eliasberg ${ }^{2}$ in experimental burns in rabbits. These authors describe two stages, (1) an initial period of hyperglycaemia due to hyperactivity of the suprarenals and (2) a period of hypoglycaemia due to suprarenal exhaustion. They also record the case of two children with extensive burns in whom there was extreme hypoglycaemia and marked acetonuria.

\section{Conclusions.}

Three cases are reported in which sudden coma was associated with disturbance in carbohydrate metabolism. In none of them was the coma due to diabetes mellitus. In the first case there can be little doubt that the syndrome was caused by a lesion of the pituitary gland and in the second, though the evidence is not so strong, it is also possible that the pituitary gland was involved. The third case has not been under observation for sufficiently long a time to determine the cause of the syndrome but it is almost certainly of nervous origin.

\section{REFERENGES.}

1. Eckstein, A., Acta paediat., Uppsala, 1933, XVI, 601.

2. Greenwald, H. M., \& Eliasberg, H., Am. J. Med. Sci., Philad., 1926, CLXXI, 682. 